\author{
Шацкая Елена Юрьевна
}

\title{
МЕТОДОЛОГИЧЕСКИЕ АСПЕКТЫ УПРАВЛЕНИЯ МЕЖДУНАРОДНОЙ МАРКЕТИНГОВОЙ ДЕЯТЕЛЬНОСТЬЮ ФИРМЫ
}

В работе исследуется значение и роль маркетинговой деятельности в современных экономических условиях, показана особенность маркетинговой деятельности на международном рынке. Обоснована значимость в современной практике организачии маркетингового подхода; роль управления; уточнень принций, лежацие в основе маркетингового подхода. Использование системного подхода в рассмотрении вопросов управления международной маркетинговой деятельностью фирмы позволяет исследовать объект как комплекс взаимосвязанных подсистем с определенными внутренними и внешними связями: разработана модель управления международной маркетинговой деятельностью фирмы.

Ключевые слова: маркетинговая деятельность, международный рынок, менеджмент, управление маркетингом.

\section{Elena Shatskaya \\ METHODS OF ORGANIZING INTERNATIONAL MARKETING ACTIVITIES OF FIRMS}

The paper examines the importance and role of marketing activities in modern economic conditions, shows the feature of marketing activities in the international market. The importance in modern practice of the marketing approach; the role of management; clarified the principles underlying the marketing approach. The use of a systematic approach to the management of international marketing activities of the company allows us to explore the object as a set of interrelated subsystems with certain internal and external relations: a model of management of international marketing activities of the company.

Key words: marketing activities, international market, management, marketing management.

Bведение / Introduction. В современных условиях глобализации и развития мирохозяйственных связей возрастает роль организации международной маркетинговой деятельности. Маркетинг является одним из самых важных видов экономической и социальной деятельности организации. Маркетинг ориентирован на повышение качества продукции, повышение продаж, которые, в свою очередь, позволят улучшить качество и уровень жизни в стране. Маркетинговая деятельность является основой функционирования любой организации. В настоящее время существует необходимость систематизировать имеющееся множество знаний.

Роль маркетинговой деятельности организации в комплексном исследовании рынка состоит в том, чтобы определить текущую и будущую стоимость спроса для разработки определенных программ, которые направлены на укрепление позиции организации на рынке, увеличение продаж, тем самым обеспечивая заданное количество прибыли.

Экономическое развитие в стране подводит российские организации к тому, что они должны быть осведомлены о проблемах необходимости маркетинговых задач в своей повседневной деятельности.

Тем не менее, это требует не только подготовленных специалистов, но и определенные усилия по созданию управленческих структур и задач, которые заключается в планировании, организации и контроля маркетинговой деятельности. Правильно спроектированная маркетинговая деятельность организации - одна из главных задач предпринимательской деятельности. В настоящее время, строительству и управлению маркетинговой деятельности уделяется все больше внимания, по сути, она является гарантом успеха и процветания организации. 
Таким образом, задача исследования проблем управления международной маркетинговой деятельностью фирмы обладает значительным научным потенциалом, а ее решение представляется актуальным с позиции теории, методики и практики.

Теоретико-концептуальные вопросы маркетинговой деятельности освещены в работах таких зарубежных авторов, как Ж. Ж. Ламбен, Ф. Котлер, Б. Берман, Дж. Эванса, Р. Баззел, Р. Браун, Л. Роджерс, Г. Хардинг, П. Уолтон, и др. и в работах российских исследователей, таких как: Г. А. Багиев, А. Г. Будрин, И. А. Аренков, С. Г. Божук, О. А. Третьяк, О. К. Ойнер, Е. П. Голубкова, И. Н. Герчикова, Д. В. Соловьева, Н. К. Моисеева, В. И. Черенков и др.

Проведенный анализ позволяет сделать вывод об отсутствии единой методологической базы управления международной маркетинговой деятельностью фирмы, о фрагментарном описании отдельных вопросов, недостаточной степени адаптации методов и принципов к современным условиях деятельности фирм.

Maтериалы и методы / Materials and methods. Исследование в методологическом плане опирается на методы логического, системного и сравнительного анализа, обобщения и сравнения.

Результаты и обсуждение /Results and discussion. В настоящее время маркетинговая деятельность является неотьемлемой частью управления любой организации. Маркетинговый подход в современном менеджменте может быть понят прежде всего как рыночно ориентированная система управления [1]. Это управление с ориентацией на запросы рынка, и его основополагающий принцип - ориентация на эффективное решение проблем конкретных потребителей.

Маркетинговый подход учитывает общую направленность управляющей подсистемы управления, чтобы решить все проблемы покупателя. По сути, это рыночный стиль управления. С учетом международного аспекта можно дать следующее определение: маркетинговая деятельность международной компании - вид специфической хозяйственной деятельности, направленный на выявление и удовлетворение потребностей потребителей на международном рынке посредством применения маркетинговых инструментов.

Содержание международной маркетинговой деятельности, по мнению автора, свидетельствует о необходимости построения единой методологии.

Анализ направлений и подходов к управлению маркетинговой деятельностью, компонентов управления позволил предложить модель управления международной маркетинговой деятельностью фирмы, представленную на рис. 1, где МД - маркетинговая деятельность.

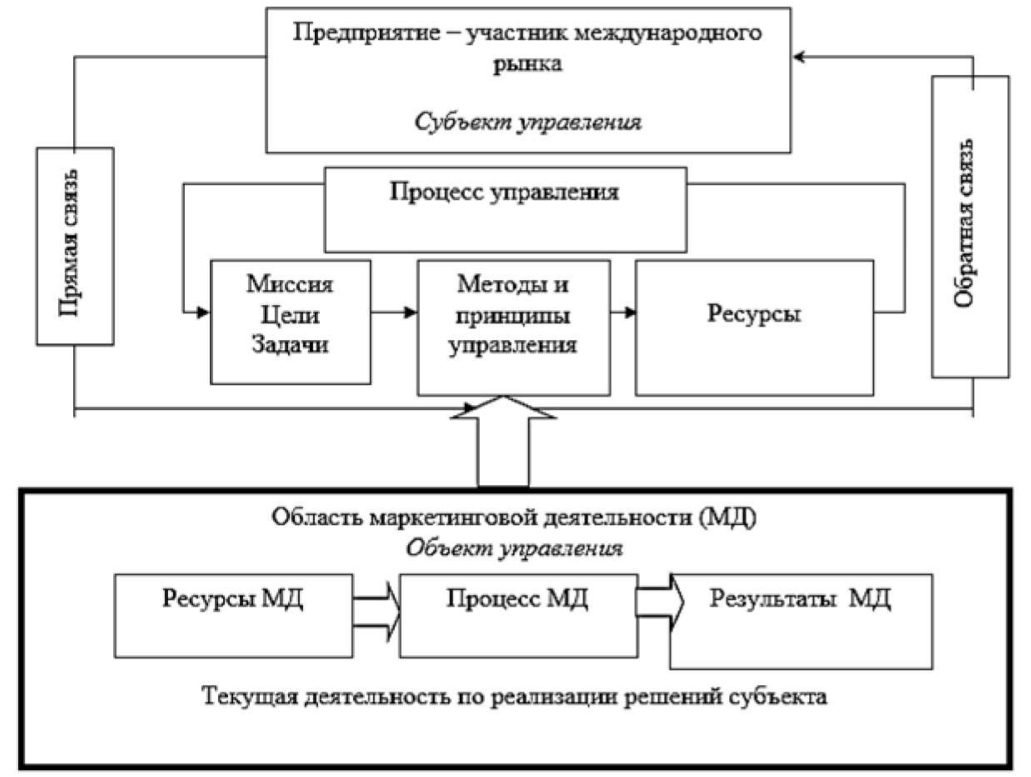

Рис. 1. Модель управления международной маркетинговой деятельностью фирмы 
Процесс управления должен строиться на следующих принципах:

- владение актуальной и многосторонней информацией о рынках, товарах и т. д.;

- $\quad$ вовлечение персонала всех служб предприятия в управление маркетинговой деятельностью;

- ответственность;

- учет национальных, культурных различий потребителей.

Выбор методики выхода организации на международный рынок зависит от таких факторов, как стоимость, уровень риска, контроль за всеми текущими процессами в организации и ряда других.

Использование системного подхода в рассмотрении вопросов управления международной маркетинговой деятельностью фирмы позволяет исследовать объект, как комплекс взаимосвязанных подсистем с определенными внутренними и внешними связями. Нами разработана блок-схема модели (рис. 2).

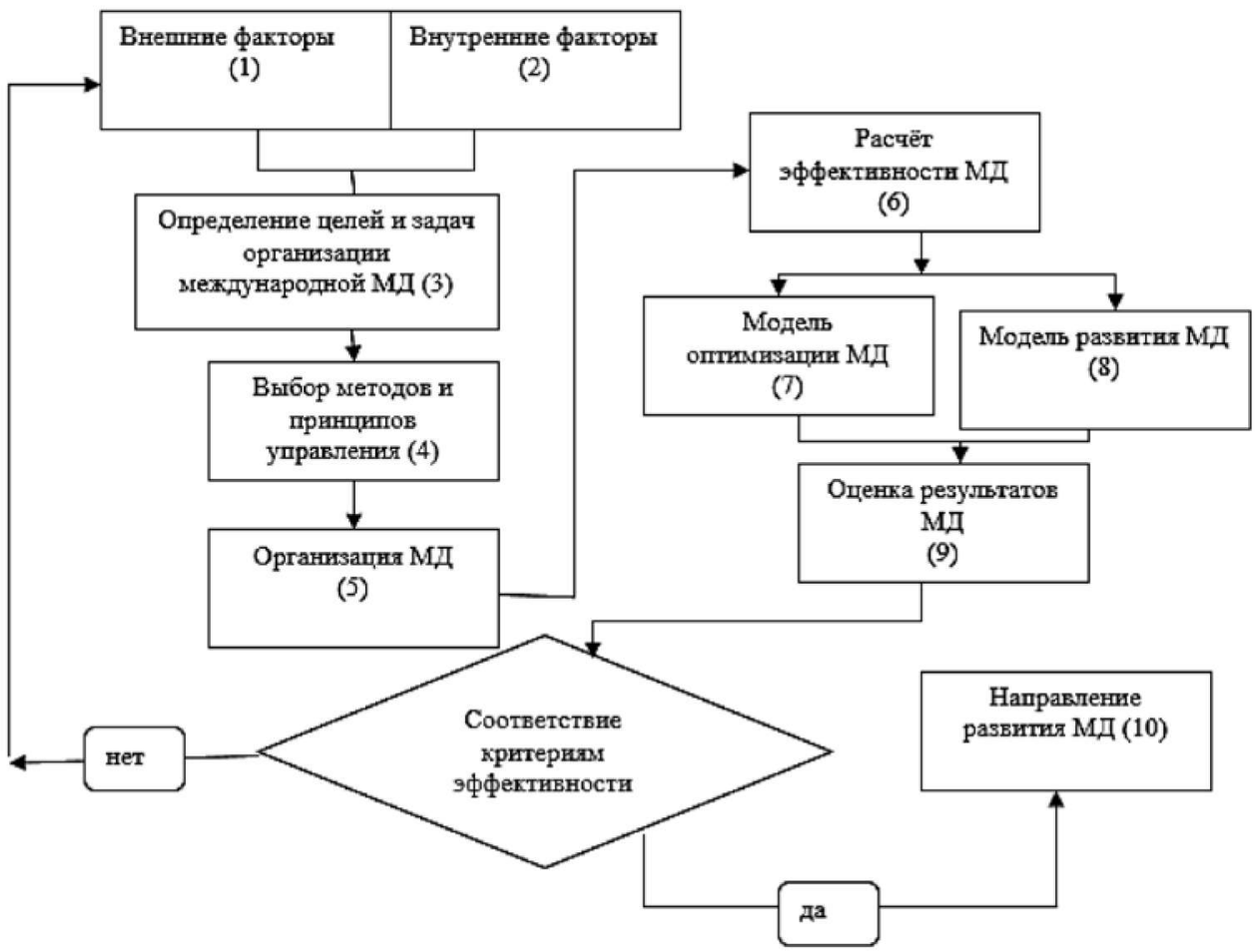

Рис. 2. Блок-схема управления международной маркетинговой деятельностью фирмы

Данная схема может упростить задачу управления международной маркетинговой деятельностью фирмы.

Заключение / Conclusion. Наиболее важные результаты исследования заключаются в следующем: обоснована значимость использования в современной практике предприятий маркетингового подхода; уточнены принципы, лежащие в основе маркетингового подхода; разработана модель управления международной маркетинговой деятельностью фирмы.

\section{ЛИТЕРАТУРА И ИНТЕРНЕТ-РЕСУРСЫ}

1. Основы менеджмента: учебное пособие / М. А. Чернышев, Э. М. Коротков, И. Ю. Солдатова; под ред. проф. И. Ю. Солдатовой. М.: ИТК «Дашков и К», МАИК «Наука / Интерпериодика»; Наука-Пресс, 2006. 
2. Багиев Г. Л., Маркетинг: терминологический словарь: учебное пособие. М., 2010. 245 с.

3. Бебрис А. О. Успешный маркетинговый подход как основа выбора инновационной стратегии развития компании // Актуальные проблемы гуманитарных и естественных наук / под общ. ред. А. О. Бебрис. М., 2013. С. 161.

4. Shatskaya E. Yu., Esaulova I. G. Market and challenges of family business based on the example of Spanish company - Vigar // Международный журнал гуманитарных и естественных наук. 2016. № 2. Новосибирск: Капитал. С. 95-99.

\section{REFERENCES AND INTERNET RESOURCES}

1. Osnovy menedzhmenta (Fundamentals of Management): uchebnoe posobie / M. A. CHernyshev, E. M. Korotkov, I. YU. Soldatova / pod red. prof. I. YU. Soldatovoj. M.: «Dashkov i $\mathrm{K}^{\circ} »$, MAIK «NAUKA / INTERPERIODIKA»; Nauka-Press, 2006.

2. Bagiev G. L. Marketing: terminologicheskij slovar' (Marketing: terminological dictionary): uchebnoe posobie. M., 2010. $245 \mathrm{p}$.

3. Bebris A. O. Uspeshnyj marketingovyj podhod kak osnova vybora innovacionnoj strategii razvitiya kompanii (Successful marketing approach as a basis for choosing an innovative development strategy for the company) // Aktual'nye problemy gumanitarnyh i estestvennyh nauk / pod obshchej red. A.O. Bebris. M., 2013. P. 161.

4. Shatskaya E. Yu., Esaulova I. G. Market and challenges of family business based on the example of Spanish company - Vigar // Mezhdunarodnyj zhurnal gumanitarnyh i estestvennyh nauk. 2016. № 2. Novosibirsk: Kapital. Pp. 95-99.

\section{СВЕДЕНИЯ ОБ АВТОРЕ}

Шацкая Елена Юрьевна, кандидат экономических наук, доцент, доцент кафедры менеджмента Института экономики и управления Северо-Кавказского федерального университета, г. Ставрополь. E-mail: nauka10@list.ru

\section{INFORMATION ABOUT AUTHOR}

Shatskaya Elena, $\mathrm{PhD}$, associate Professor of Management Department, Institute of Economics and management, North Caucasus Federal University, Stavropol. E-mail: nauka10@list.ru 